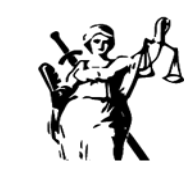

JUSTICIA

ISSN impreso 0124-7447
ISSN digital 2590-4566

\title{
Mediación para la reducción de los conflictos interpersonales en el contexto organizacional
}

\section{Mediation for the reduction of interpersonal conflicts in the organizational context}

\author{
(iD) \\ Francisco Javier Gorjón Gómez \\ Universidad Autónoma Nuevo León de México \\ fgorjon@hotmail.com
}

\author{
Luz Marina Ramón Monje \\ Universidad Simón Bolivar, Colombia \\ Iramon@unisimonbolivar.edu.co
}

Recibido: 14 de mayo de 2020 / Aceptado: 26 de julio de 2020 https://doi.org/10.17081/just.26.39.4690

\begin{abstract}
Resumen
La naturaleza subjetiva de los conflictos y su inminencia en las relaciones humanas suscita la constante reflexión de como dinamizarlos para alcanzar acuerdos oportunos, asertivos y sostenibles al interior de las organizaciones. En la búsqueda de esta dinamización surge mediación de los conflictos interpersonales en el ámbito laboral como una alternativa válida y confiable. Este artículo de reflexión se constituye en una investigación documental que tiene por objetivo aproximarse a visibilizar el rol del mediador al interior de las organizaciones, delimitar planes de intervención y/o políticas de gestión del conflicto desde la alta gerencia, así como crear material formativo sólido y rigurosos, que sea soporte y guía para las áreas de recursos humanos y/o comités de Seguridad y Salud en el Trabajo.
\end{abstract}

Palabras CLAVE: mediación, conflicto laboral interpersonal, riesgo psicosocial, gestión, salud mental laboral.

\begin{abstract}
The subjective nature of conflicts and their imminence in human relationships raises constant reflection on how to dynamize them to reach timely, assertive and sustainable agreements within organizations. In the search for this dynamization, mediation of interpersonal conflicts in the workplace arises as a valid and reliable alternative. This article of reflection is constituted in a documentary research that aims to approach to make visible the role of the mediator within organizations, define intervention plans and / or conflict management policies from senior management, as well as create solid training material and rigorous, that is support and guide for the areas of human resources and / or committees of Safety and Health at Work.
\end{abstract}

KEYWORDS: mediation, interpersonal labor conflict, psychosocial risk, management, occupational mental health.

Como Citar: Ramón Monje, L. M., \& Gorjón Gómez, F. J. (2021). Mediación para la reducción de los conflictos interpersonales en el contexto organizacional. Justicia, 26(39), 1-24. https://doi.org/10.17081/just.26.39.4690 


\section{Introducción.}

La naturaleza multidisciplinar de los métodos alternos para solución de conflictos, así como su connotación de ciencia social emergente, los ha llevado a erigirse como la apuesta por excelencia frente al abordaje de las controversias (Gorjón \& José, 2020), acercándonos a la justicia desde una perspectiva de equidad.

El contexto de las organizaciones no es ajeno a los conflictos de carácter interpersonal, de hecho, han sido ampliamente abordados a lo largo de la historia como parte de las políticas de la alta dirección y adherido a los diferentes programas de gestión de personal, bienestar y cultura organizacional; En la actualidad, esta temática ha tomado un nuevo matiz, pues ya no solo se habla de la importancia de un buen clima laboral en sí mismo o para fines de procesos de calidad, de producción y/o de servicio al cliente, sino que también se ha vinculado en diversas investigaciones con la salud mental del sujeto laboral (Caicero, 2015).

Esta investigación de tipo documental, hace todo un abordaje de la necesaria reflexión de los conflictos laborales interpersonales desde la importancia de garantizar condiciones laborales saludables a todo nivel, planteando la inminente naturaleza perceptual e intangible inmersa en las relaciones humanas, en un esfuerzo por posicionar la mediación y el rol de la misma dentro de las organizaciones, como la consecuente vía hacia la armonía, el bienestar, y por ende, en aporte a la salud mental laboral.

\section{Resultados}

\section{La salud mental laboral como derecho: doctrina y norma.}

El concepto de salud mental ha estado históricamente marcado por un estigma de prejuicio social, en general, las personas no suelen apersonarse de esta como si lo hacen de su salud física; ahora bien, tras el proceso de concienciar a la población sobre la naturaleza integral del ser humano y la importancia de atender de manera oportuna las situaciones ansiógenas están tanto organizaciones de renombre internacional como la Organización de Naciones Unidas con su programa para el trabajo decente (ONU, Objetivos de Desarrollo del Milenio, 2015) (ONU, 2018), Organización Mundial de la Salud con su informe para entornos laborales saludables (OMS, 2010), la Organización Iberoamericana de Seguridad Social y su plan de condiciones de seguridad y salud en el trabajo (OISS, 2014), y la Organización Internacional del Trabajo con su sistema de seguridad y salud en el trabajo (OIT, Sitema de gestión de la seguridad y salud en el trabajo, 2011) (OIT, 2017), así como agremiaciones académicas, investigadores independiente, fundaciones locales, y por supuesto, las organizaciones de naturaleza empresarial, por mencionar algunas.

En Colombia, la resolución 2646 de 2008 supone el primero y principal marco jurídico de la salud mental laboral, categoriza el concepto de factor de riesgo psicosocial y aporta elementos para evidenciar el conflicto interpersonal al interior de las organizaciones, sustentando la obligatoriedad de cumplimiento para las empresas. Aunque no determina modelos de intervención, sirve como argumento jurídico para dar vía a la implementación de la mediación, ya sea desde una estrategia contextual donde el mediador es solo un facilitador que cambia las condiciones del conflicto para que las partes llegue por sí mismas al acuerdo, o substantivas donde el mediador suscita el acuerdo (Lim \& Carnevale, 1990).

Para el caso particular de Colombia, abordar la salud mental laboral implica atender de manera preventiva y correctiva el riesgo psicosocial, entendiéndose este como "las condiciones presentes en una situación laboral directamente relacionadas con la organización del trabajo, con el contenido del puesto, con la realización de la tarea e incluso con el entorno, que tienen la capacidad de afectar al desarrollo del trabajo y a la salud de las personas trabajadoras" (Gil-Monte, 2009). Vale la pena mencionar que los facto- 
res psicosociales pueden favorecer al individuo fomentando su desarrollo y rendimiento laboral o por el contario perjudicándolo (Gil, 2012), pues las características del empleo (diseño del lugar de trabajo, salario que se recibe, estabilidad contractual, condiciones físicas, duración y tipo de jornada, pausas, entre otras) son determinantes al momento de abordar la salud mental laboral (Decreto No. 1443, 2014).

La legislación colombiana cuenta con la virtud de estar nutridamente reglamentada en materia de seguridad y salud en el trabajo, espacio jurídico donde se anida el factor de riesgo psicosocial encargado de velar por la salud mental laboral. Entiéndase por psicosocial en el contexto organizacional como esas “interacciones entre el trabajo, su medio ambiente, la satisfacción en el trabajo y las condiciones de su organización, por una parte; y por la otra, las capacidades del trabajador, sus necesidades, su cultura y su situación personal fuera del trabajo, todo lo cual, a través de percepciones y experiencias, pueden influir en la salud y en el rendimiento y la satisfacción en el trabajo" (OIT, 1984)

Es precisamente en el campo experiencial donde se suscitan inconsistencias reiteradas en las relaciones laborales, que pueden dar lugar a la intervención mediadora para equilibrar las relaciones entre los sujetos que protagonizan el conflicto; al advertir la Ley 1010 de 2006 (CRC, 2006), el nicho adhoc de la mediación laboral en los conflictos interpersonales, dado que aporta los lineamientos básicos a las organizaciones sobre este y otros tipos de controversias, y de paso las compromete en su identificación e intervención.

El reto entonces, en materia de viabilizar la intervención mediadora, es suscribir un espacio estratégico donde la naturaleza comercial de las organizaciones laborales pueda implementarla sin perjuicio de la rentabilidad de los procesos, para esto la Resolución 0652 de 2012 (MinTrabajo, 2012), estructura un subsistema dentro de la organización, encargado de dar manejo en primera instancia, a los diferentes conflictos y especialmente, casos de acoso que se presenten en el espacio laboral; aunque su filosofía se basa en prevenir el desgaste para la identidad e imagen corporativa que supone una denuncia de acoso laboral, también pone en agenda los conflictos interpersonales y alerta sobre la conformación de un colegaje que participe de manera activa en la resolución oportuna de los mismos, lo que constituye uno de los principios filosóficos de la mediación.

Aunque el gobierno colombiano en su norma (resolución 2404 de 2019) provee elementos prácticos en relación con el factor de riesgo psicosocial, dentro de los cuales se encuentran baterías diagnósticas, guías y protocolos (MinTrabajo, 2019), que vinculan el conflicto interpersonal y sus efectos, lo interesante para el campo de los métodos alternos, es que especifica la importancia de un abordaje multidisciplinar para el “diseño, orientación y desarrollo de las actividades de prevención y control" del citado factor; así las cosas, es el conflicto interpersonal una fuente de riesgo psicosocial y la mediación una estrategia competente para su intervención.

La normatividad descrita aborda de manera directa o parcial, pero detallada y cuidadosamente, la evaluación, prevención e intervención del factor de riesgo psicosocial y por ende la salud mental laboral, todo compilado en el Decreto 1072 de 2015 y actualizado en 2016 (MinTrabajo, 2016).

Así las cosas, el riesgo psicosocial pone en escena situaciones no resueltas, ante las cuales el trabajador disminuye su motivación, productividad y conductas de autocuidado o seguridad laboral, pues es considerable la carga mental que produce en el trabajador factores externos a la tarea, que se encuentran en su entorno de trabajo (Ceballos, y otros, 2015); Y es que un entorno laboral saludable debe ser la convergencia entre ausencia de circunstancias perjudiciales y factores que promueven la salud (Gutiérrez \& Viloría, 2014).

Ahora bien, ahondar en las diferentes variables que afectan la salud mental laboral del trabajador es un tema de estudio tan amplio como diverso; una de ellas y de interés para la presente investigación, es 
el conflicto interpersonal, y los MASC, la apuesta de intervención que propicia la prevención de las consecuencias ya descritas en esta sección.

\section{Los métodos alternos en el contexto organizacional.}

Según estadísticas del Ministerio de Trabajo Colombiano entre 2014 y 2018 se han presentado cerca de 282.000 conflictos individuales y casi 6.000 colectivos en el ámbito laboral (Morales, 2018), tema que ocupa a la Comisión Permanente de Concertación de Políticas Salariales y Laborales; lastimosamente, pese a que la normatividad vigente incluye como paso pre-jurídico la conciliación para dirimir los conflictos colectivos e individuales en el ámbito organizacional, en la mayoría de los casos es la empresa quien se niega a conciliar, dando paso a la obra de los inspectores de trabajo designados por el Ministerio de Trabajo, pero que en la actualidad, cuentan con una somera capacidad instalada, evidenciando un panorama poco alentador para las MASC.

Ahora bien, cuando se trata del conflicto laboral, la mediación no se encuentra tipificada en el marco de las relaciones laborales (Arastey, 2015), es más, en el caso de Colombia se diluye como un rol entre los pasos de la conciliación, negociación y el arbitraje de los conflictos laborales colectivos, o sea, los sindicalizados.

Pero ¿cómo los sujetos laborales no sindicalizados están lidiando con los conflictos interpersonales? Pese a que es bien conocido el coste que para la salud mental tiene el conflicto y que la infructuosa resolución de estos se constituye en sí mismo un factor de riesgo psicosocial (Ahumada, 2008), no existen estadísticas al respecto; por tanto, se requiere analizar la relación tríadica sujeto laboral - conflicto interpersonal - estrategias de pacificación, desde la premisa de la superposición de personas, grupos y organizaciones en conflicto (Pastor, 2013), lo cual da lugar al uso de la mediación por su naturaleza axiológica.

Esta complejidad, propia de los conflictos interpersonales al interior de las organizaciones, es el escenario ideal de acción de los métodos alternos en solución de conflictos, apuesta teórica que se ha venido gestando disciplinadamente desde la academia (Gorjón F. , 2014), en respuesta a las limitaciones del aparato judicial; los MASC constituyen un alivio en tiempo y forma, de los desgastados procesos jurídicos tradicionales y han logrado demostrar, pese a su relativamente reciente nacimiento, su valía y operatividad funcional (Gorjón F. , 2015).

Ya aplicado al contexto de las organizaciones, los MASC se han logrado posicionar con firmeza cuando de conflictos colectivos se trata, ya sea conflictos de naturaleza jurídica o de intereses; frente a la cuestión de cuál de los MASC es el más idóneo para atender el conflicto interpersonal, prevalece la mediación desde sus fases constitutivas: prevención, educación e intervención, al articularse estratégicamente a las necesidades que se atienden en el Comité de Convivencia Laboral (MinTrabajo, 2012) figura ya descrita en el subcapitulado anterior.

Esta legislación, además de tipificar al menos seis formas de acoso laboral (maltrato, persecución, discriminación, entorpecimiento, inequidad y desprotección), establece como medida preventiva y correctiva en su artículo noveno, la conformación de un comité encargado de intervenir dichos comportamientos, mediante el diseño de procedimientos internos de carácter confidencial y de ánimo conciliatorio; pero lastimosamente se limita al ámbito de la gestión y el trámite de la queja, no define competencias de sus miembros, rol del sujeto mediador, principios que encuadren los encuentros conciliatorios, ni tampoco algún tipo de modelo que sirva como garante de un procedimiento que lleve a buen término el trámite de la queja. 
Así pues, mientras la normatividad vigente insta a las organizaciones a la multidisciplinariedad en pro de la efectividad, la mediación se instaura como esa efigie que sitúa a las partes en un plano de igualdad, logrando que se involucren directamente en la solución de las disputas suscitadas en el desarrollo de las relaciones laborales (Cedalise, 2020).

La mediación supone la propia responsabilidad de los actores del conflicto para generar los acuerdos resolutivos, lo que abona a la construcción de un sentido de colectivo comunitario, escenario ideal de la cultura organizacional (Chiaventado, 2007); Pese a este protagonismo de las partes, el rol del tercero objetivo constituye el puente de comunicación de ese escenario belicoso, procurando la armonización del disenso, atacando el verdadero enemigo entre las partes: el conflicto (González \& Steele, 2020).

Articular la mediación como método alterno hacia la pacificación de los conflictos laborales al interior de las organizaciones requiere, primordialmente, la intención positiva de la alta dirección de instituirla como una política de bienestar (Gorjón F. , 2020) y, preferencialmente, una cama legal que le permita anidarse con fundamento de causa para su uso y dinamización; La Ley 1010 de 2006 por medio de la cual se adoptan medidas para prevenir, corregir y sancionar el acoso laboral y otros hostigamientos en el marco de las relaciones de trabajo (CNC, 2006), representa el andamiaje jurídico perfecto para sustentar la mediación dentro de la ya mencionada figura Comité de Convivencia Laboral.

Es precisamente este panorama el que invita a la creación de nuevas apuestas hacia la pacificación de los conflictos interpersonales en el ámbito laboral, pues "aun cuando los conflictos laborales son conflictos entre partes, no dejan de tener un efecto en la comunidad" (Garza, 2016), por ende en el clima, una de las variables más importantes cuando de Cultura Organizacional se habla.

\section{Los conflictos interpersonales laborales y la mediación de lo inicuo en el contexto organizacional.}

En la condición humana, la confrontación es una de esas estrategias cognitivas evolutivas, que forman parte de nuestro repertorio genético y se transforma de acuerdo a las situaciones vividas (Montealegre, 2007). Ahora bien, discursar sobre lo natural o no que pueda ser el conflicto, es tan solo una de las líneas cuando se trata de comprender como este ha formado parte históricamente de nuestra especie; los intereses divergentes, las posturas incompatibles, luchas de poderes oblicuos, por mencionar algunos modelos, siempre han estado presentes en las dinámicas de los grupos sociales, definir una postura para su análisis he intervención es de vital importancia.

La ruptura del diálogo alerta la llegada del conflicto, pues de alguna manera se renuncia a esa conexión natural del carácter social vinculante con los otros, a la posibilidad de seguir tejiendo propositivamente sentidos mutuamente. Lerechar plantea tres dimensiones a saber, una racional donde se cambie la perspectiva negativa que tradicionalmente se le ha dado al conflicto, una estructural para hablar de patrones que privilegien el orden social bajo una premisa de no violencia, y uno cultural que habla de sus efectos en las estructuras sociales y la comprensión de las dinámicas propias de cada grupo para incluirlas en herramientas de construcción y activo de paz (Lerechar, 2003).

Esta dimensión cultural plantea la dinámica del conflicto en una consecuente respuesta de equilibrio relativo entre las partes, es la meta final cuando de armonía se trata, la interacción entre divergencia y control social ejercido por el grupo para rescatar el orden. Así las cosas, no habría posturas de vencedores ni vencidos, sólo que el orden y la estabilidad social. Los vínculos que se establecen a razón del conflicto son más que suficiente para justificar la necesidad de su existencia (Silva, 2008). 
Solucionar y gestionar el conflicto parece insuficiente, probablemente por la tradicional carga negativa que se le ha dado a la palabra, lo cual invisibiliza el carácter orgánico que en nuestra naturaleza social representa. El termino transformación para asumir el conflicto, representa una búsqueda pedagógica constructiva por respetar la presencia del conflicto en la evolución de la especie humana, donde las soluciones nazcan de las particularidades de cada sujeto, y que sin aspirar a que se perpetúe, al menos si permanecer en una actitud de abierta escucha y pensamiento flexible a los impredecibles cambios de la vida misma (Muñoz, 2001).

Este carácter multidisciplinar de las visiones académicas sobre el conflicto provee una perspectiva ampliada de sus posibles causas e intervenciones, buscando alternativas de compensación, e incluso incentivos de inclusión, para hacer de esta una sociedad más tendiente a la convivencia pacífica. Con que recursos contamos, que expectativas hay entorno a la cuestión y como se desarrolla el conflicto, es hacia donde se enfocan los esfuerzos, pues más allá de las múltiples contradicciones en los postulados teóricos está el hecho real de que todos anhelamos vivir en paz, en armonía (Gorjón F. , Mediación como vía al bienestar y la felicidad, 2020), y el mundo laboral no es la excepción.

\section{La mediación de los conflictos interpersonales laborales en el contexto organizacional.}

Como ya se había mencionado anteriormente la mediación como MASC no cuenta con una figura jurídica para Colombia pues se plantea más bien como una figura de oficio no de modo, es el aval del amplísimo constructo normativo y teórico a nivel internacional lo que inspira su implementación en el ámbito organizacional (Cedalise, 2019); considerando también las sutiles diferencias que, entre divergencias y convergencias conceptuales, provee la literatura en relación a la figura de la conciliación, la cual si se encuentra normatizada y regulada en el país.

La conciliación en equidad (CNC, 1991), concepto citado en la Ley 23 de 1991 en sus artículos del 82 al 89 contiene lo más parecido para Colombia a la estructura de la mediación que dicta la generalidad en la norma internacional; más adelante con la Ley 640 de 2001 se retoma sin más detalle este título en su artículo 3 (CNC, 2001).

Ahora bien, la conciliación y la mediación se constituyen como alternativas no adversariales para la pacificación de los conflictos (Cabello, 2018), pero ratificar la mediación como la alternativa por excelencia para intervenir los conflictos interpersonales laborales, se justifica en el determinante protagonismo que se le da a las partes, pues esta responde prioritariamente a sus intereses, propendiendo porque se comuniquen lo suficiente para llegar por su propia cuenta a los términos conciliatorios, proveyéndolos así de un amplio control de todo el proceso, mientras mantiene en su rol la figura del tercero imparcial y neutral (Medina, 2007).

Llevar a la práctica un ejercicio de mediación de los conflictos interpersonales en el ámbito laboral implica inicialmente crear un marco del conflicto donde se identifique con claridad las partes involucradas, los intereses de cada una de las partes, los factores transversales de contexto y la o las mejores alternativas de acuerdo negociado (Munduate, Butts, Medina, \& Martínez-Pecino, 2017); respetando los principios de confidencialidad, equidad, flexibilidad, honestidad, independencia, imparcialidad, neutralidad y voluntariedad (Gorjón F. , 2016).

Pero esto es solo el proceso de arranque, las organizaciones están llamadas a debatir la viabilidad de la mediación como parte intrínseca a sus procesos de gestión humana (Mansilla, 2012); como se ha propuesto 
a lo largo de este capítulo, este MASC se puede incluir en el marco del cumplimiento del Decreto 1072 de 2015, implementándolo como parte de la estructura definida para el Comité de Convivencia Laboral en la Resolución 0652 de 2012. Dado que todas las quejas formales, por política de estado, deben ser atendidas por el mencionado comité, solo haría falta institucionalizar al interior de la organización la mediación como paso subsecuente a la recepción de la queja, respetando los protocolos axiológicos de la misma.

Para tales fines, se tendrá que establecer el procedimiento de mediación a implementar, esta investigación propone el modelo desarrollado por el Sistema Extrajudicial de Resolución de Conflictos Laborales en Andalucía (SERCLA, 2004):

$\gg$ Preparación de la dinámica del equipo mediador: Reunión previa del equipo de mediadores donde programa y proyecta el proceso de mediación, gracias al primer encuentro entre las partes, ya se conocen las preferencias y debilidades de cada uno, asi se pueden dividir las tareas y trabajar colaborativamente. La idea es exponer el caso brevemente para gestionar las dinámicas más adecuadas.

Este paso se articula con las reuniones periódicas que por ley debe hacer el Comité de Convivencia Laboral escenario donde se puede poner al equipo en contexto del conflicto y explorar la forma como se dará el primer encuentro entre las partes. Inicialmente se debe contemplar que, dentro de los tres tipos básicos de mediador, los miembros de dicho comité que fujan como tal estarían dentro del nivel de practicantes no profesionales de la mediación (González \& Steele, 2020).

$\gg$ Presentación de la comisión y del proceso como primera parte de esta fase: Se busca describir la función del equipo mediador y responder a cualquier inquietud, así como el resalta la responsabilidad de cada una de las partes en el proceso de negociación; de igual forma se firma un acuerdo para establecer una relación de confianza en el proceso y en el equipo.

En esta etapa el acuerdo de mediación es protagonista, por tal razón los miembros del Comité de Convivencia Laboral deben contar con la cualificación necesaria para su diseño y ejecución. Es importante destacar que de la claridad y dominio que proyecte el sujeto mediador en este espacio, dependerá en gran medida la percepción de credibilidad del proceso.

Para llegar enfocados a este espacio, es importante articular dos elementos que no contempla la norma colombiana en el ámbito de los conflictos interpersonales laborales, pero que son perfectamente válidos y viables desde el punto de vista del direccionamiento estratégico; esto incluye en primera instancia, a quien se le adjudique la figura de mediador debe cumplir con las competencias personales y actitudinales tales como neutralidad, flexibilidad de discurso, inteligencia, paciencia, empatía, sensibilidad, respeto, escucha activa, creatividad, persuasivo, objetivo, habilidad para no personalizar, honestidad, ser digno de confianza, sentido del humor y perseverancia entre otras (González \& Steele, 2020).

En segunda instancia tener claridad en modo y forma, y hacer estricto cumplimiento, a los principios de la mediación, consenso internacional entre los cuales se encuentran: confidencialidad, equidad, flexibilidad, honestidad, independencia, imparcialidad, neutralidad y voluntariedad.

$\gg$ Recabar información y exploración del problema como segunda parte de esta fase: Se recolecta la mayor información posible sobre la situación de conflicto, para así orientar las siguientes etapas del análisis de las posibles alternativas; se invita a cada una de las partes a narrar su versión de los hechos, a través de preguntas abiertas, mientras el equipo mediador va realizando anotaciones, continua formulando preguntas y plantea aclaraciones, centrándose en el diálogo y alejándose de posiciones rígidas. 
Los conflictos interpersonales en el ámbito organizacional se contemplan en el marco de los conflictos de intereses, por tanto, la naturaleza perceptual de los hechos juega un papel muy importante. Identificar la génesis del conflicto es una de las habilidades del sujeto mediador idóneo; esto representa un reto para los miembros del Comité de Convivencia Laboral no cualificados, dado que estamos abordando un espació que filosóficamente está diseñado para la resolución pacífica de las controversias, pero normativamente carece de la institucionalidad de los MASC.

$\gg$ Comunicación entre los miembros del equipo mediador para determinar las siguientes actuaciones: Los mediadores resumen la información en función de los temas identificados con anterioridad, normalmente se lleva acabo frente a las partes pidiendo su colaboración para que ellos se sientan protagonistas del mismo proceso y al final pueden generar soluciones.

En relación al lugar que se formula ocupe la mediación de lo inicuo en las organizaciones, más que un equipo mediador, se propone un delegado del Comité de Convivencia Laboral que funja como tal; este numeral se articularia como una muestra de avances en el proceso, respetando la confidencialidad del mismo y consultando con las diferentes vías en congruencia con las políticas de la alta dirección.

$\#$ Generación de opciones sin compromiso siempre en presencia de todos los miembros del equipo mediador: Se busca cambiar las posiciones conflictivas de las partes, orientándolas a los intereses de cada una de ellas, en un ambiente de diálogo y colaboración; se estimula la creatividad para la formulación de alternativas de solución del problema, alternativas que deben ser flexibles y sin compromiso fijo.

La habitual política de Bienestar Laboral que manejan las organizaciones crea el ambiente ideal para esta formulación, solo que este espacio se trabaja desde la particularidad de las partes y en la intimidad del espacio que provee el ejercicio de mediación.

$\gg$ Valoración de las opciones: esta fase se orienta a evaluar las alternativas propuestas anteriormente para ver si alguna satisface los intereses de todas las partes implicadas o bien se modifica para lograr el objetivo aquellas que resultan viables se valora nuevamente en base a lo que se tiene que hacer y sus posibles consecuencias.

Al igual que el punto anterior, si las políticas organizacionales han premiado la generación de espacios creativos y dialógicos, el sujeto designado en el rol de mediador podrá promover los pros y contras en un espacio de camaradería y respeto.

$\gg$ Discutir y seleccionar entre opciones y alternativas generadas: Esta es la fase de la negociación de las alternativas, el equipo mediador les ayuda a las partes a definir una solución adecuada destrabando posiciones, evitando estancamientos mediante diversas estrategias tales como la reformulación de preguntas, recordar las posibles consecuencias de no conciliar, enfatizar en los preacuerdos, proveer más información hacía una nueva perspectiva, formular un periodo de prueba, entre otras.

Dado que el sujeto mediador designado es un par, que, voluntaria y democráticamente se ha incluido como miembro del Comité de Convivencia laboral, está en el deber de mantener el delicado equilibrio entre el pensamiento individual, el colectivo y el institucional; en este caso, al mencionar las consecuencias de no dirimir, se propone mencionar, adicional a lo estipulado por el modelo, el desgaste individual y para el equipo desde la perspectiva de la salud mental laboral, así como recordar las políticas (y por ende, consecuencias) que la alta dirección tenga establecidas frente a un escenario de continua beligerancia. 
$\gg$ En caso de estancamiento propuestas del equipo mediador: Se considera un último recurso, ya que siempre se busca que las partes lleguen a la solución de manera autónoma; en este caso se debe cuidar con recelo no privilegiar a ninguna de las partes, se aconseja proveer de varias alternativas, dejando la decisión final a los mediados.

Se reitera en este apartado las políticas que desde la alta dirección tenga la organización; dado que en este contexto el sujeto mediador cumple con la triple figura par-mediador-representante de la organización, todas las propuestas que se vea forzado a diseñar en un escenario de divergencia, estarán alineadas a las políticas de bienestar y convivencia de la organización, en las cuales axiológicamente prima la salud integral del trabajador y su percepción de satisfacción laboral.

$\gg$ Cierre y clausura de la mediación: Se redacta claramente el acuerdo, cuidando cada detalles, preservando la imagen de las partes y especificando que se debe hacer en dado caso alguna de las partes se vea incapacitada para cumplir el acuerdo; se hace hincapié en que la labor del equipo mediador no es sólo lograr un acuerdo entre las partes sino también generar el compromiso de ir moldeando los comportamientos que llevaron a las partes al conflicto, para lograr un mejor entendimiento mutuo en el futuro.

Este acuerdo deberá ser expuesto ante el Comité de Convivencia Laboral, e incluido en los informes periódicos que se emiten a la alta dirección. Frente a un escenario de incumplimiento del acuerdo de mediación, se debe incluir una cláusula que respete fielmente el reglamento interno de la organización y sus políticas, mismas que deben cumplir con el debido proceso citado por el estado colombiano; una propuesta sería: "Si el acuerdo de mediación fuera incumplido por alguna de las partes en controversia, el Comité de Convivencia Laboral, derivará informe completo del proceso al área de Talento Humano, para la respectiva sanción disciplinaria/administrativa que el caso amerite"

Cada uno de los pasos antes descritos, es perfectamente amoldable a la estructura señala por la legislación colombiana para tramitar conflictos a través el Comité de Convivencia Laboral, el gran vacío estaría en quien asume el rol de Mediador; la alta dirección está llamada a determinar si es más viable contratar a un sujeto competente externo a la organización garantizando así la percepción de imparcialidad que requiere el proceso, o, formar a los miembros de dicho comité en las competencias básicas del ejercicio de mediación, opción en la cual la gerencia tendrá que, en primera instancia, cuidar con recelo que esta formación sí cumpla con los estándares mínimos de cualificación so pena de caer en un mero ejercicio de facilitador (Gorjón F. , 2019), seguidamente deberá trabajar en generar una cultura de confianza hacia estos pares que necesariamente están revestidos con el rol de autoridad.

En esta línea, y en consonancia con el modelo de Andalucía, la fundación SIMA en España (Servicio Interconfederal de Mediación y Arbitraje), consolido a manera de conferencia, informe que ubica la mediación laboral con éxito en el campo organizacional, por su efecto tranquilizante en las personas, los espacios pacificadores que fomenta, y la notable reducción de los conflictos que han logrado desde su implementación (Borrego, 2014); lo cual constituye un referente de impacto para el mundo del trabajo y las organizaciones.

Es precisamente al mencionar este rol de autoridad, del cual están revestidos los miembros del Comité de Convivencia Laboral, que nos adentramos al terreno de lo subjetivo, de lo perceptible, de lo intangible.

\section{Los intangibles en la mediación y su impacto en las organizacionales laborales.}

El constructo teórico formulado por el Phd. Francisco Javier Gorjón Gómez, en su libro "Mediación, su Valor Intangible y Efectos Operativos" (Gorjón F. , 2017), constituye el marco referencial que estructura los 
llamados Intangibles en la Mediación, apuesta teórica que consolida variables siempre presentes en las relaciones humanas pero que generalmente pasan desapercibidas; A continuación, se describe una breve abstracción personal de los intangibles propuestos por el mencionado autor y su ámbito de aplicación en el mundo del trabajo y las organizaciones:

- Activo de Paz: Necesidad presente en cada cultura, e intrínseca a su naturaleza social de convivir pacíficamente, fija a los sujetos como actores sociales desde un precepto de paz positiva.

Dado que el rol laboral ocupa gran parte de su vida cotidiana, la premisa de ambientes de trabajo saludables, donde se pueda convivir de manera pacífica en las relaciones interpersonales e intergrupales, impacta no solo en la salud mental, sino también en la percepción de paz espiritual, plenitud laboral, equilibrio entre otros. El activo de paz, es un intangible de la vida misma, y por ende, de la vida organizacional, constituye en sí mismo el estado ideal deseado de todo colectivo humano.

- Armonía: Se entiende como la convicción del cumplimiento de lo normativo y/o directivo planteado en un determinado sistema social, sea este de tipo cosmogónico o taxativo.

Este intangible se posiciona como el clima organizacional ideal, en el cual las políticas de la alta dirección y las particularidades propias de los sujetos laborales logran alinearse en un marco de acuerdo contractual y moral. Consabido es que un ambiente laboral armónico, repercute en la calidad de los procesos, lo que a su vez impacta positivamente la imagen corporativa, redundado en un mejor y mayor receptividad por parte del cliente externo. Por su parte un ambiente laboral armónico, provee elementos base para entablar un dialogo mediador y pacificador de los conflictos interpersonales, si bien es cierto el disenso siempre estará presente, establecer puentes de conexión es la clase para lograr una mediación exitosa.

- Asociatividad: Plantea los inmanentes vínculos generados en los sistemas sociales, determinantes para su evolución de los mismo, su presencia representa un factor protector.

Es ampliamente conocido el aporte de este intangible en las dinámicas laborales, conocido en la literatura administrativa como trabajo en equipo, es una variable de la cultura organizacional que dinamiza los procesos y provee un ambiente de colegaje que, entre otras cosas, aporta a la efectividad de respuesta en momentos coyunturales. Sentirse parte de un equipo de trabajo, compromete intrínsecamente al sujeto a propender siempre por la pronta resolución de las controversias; esta misma asociatividad se configura como un elemento de sostén cuanto las percepciones y emociones entran en juego durante un conflicto interpersonal, al constituirse como una red de apoyo organizacional que influye en la forma como el sujeto en cuestión asume la realidad belicosa.

- Autonomía: Basé para el cumplimiento del principio de Voluntariedad, es la construcción de una ecuánime y equilibrada relación entre mediador y mediados.

Pilar del liderazgo en los procesos organizacionales, la autonomía siempre ha formado parte cuando de gestionar el recurso humano se trata, debido al empoderamiento que suscita en el sujeto laboral, y el respectivo al alivio que da a los procesos contar con personal de estas cualidades; un sujeto autónomo, supone una actitud de búsqueda activa de soluciones frente a cualquier contexto, incluyendo el del conflicto interpersonal. Así las cosas, en un escenario cuyos sujetos laborales cuenten con esta competencia personal, es probable que se inclinen por buscar soluciones por su propia cuenta frente a la controversia, dentro del abanico de posibilidad en la cual estaría la mediación del conflicto interpersonal laboral.

- Bajo Costo: Amplía la visión costo beneficio frente a las disputas, abordando el desgaste que a nivel físico y emocional se suscita en las personas en disputa. 
Reconocer el valor de un buen acuerdo a tiempo, les permite a los miembros del equipo priorizar en su rol laboral, dejar de lado temporalmente las diferencias para llevar a buen término la función contratada, y de paso, dar el espacio necesario para las respuestas emocionales disminuyan su intensidad, anidando así el clima ideal para llegar a un racional; consabido es el coste que para los procesos organizacionales tienen las disputas no resueltas, más aún cuando estas trascienden del ámbito laboral hacia un litigio jurídico, pensar en disponer espacios de mediación de los conflictos laborales interpersonales, es incluir dentro del direccionamiento estratégico organizacional, la mediación como oportunidad de reducción de costos en diversos escenarios.

- Capital Social: Potencializa elementos circunscritos al tejido social, valida al sujeto en comunidad y estrecha lazos entre sujetos y tercero imparcial.

En el argot empresarial es lo que constituye la cultura organizacional, dado que cada organización piensa sus procesos en torno a un panorama ideal, es el capital social el que pone en evidencia los elementos cosmogónicos que los constituyen; este intangible pone en contexto la cohesión de los equipos de trabajo, la forma como generan sus imaginarios colectivos, así como la carga emocional que se le da a las situaciones conflictivas y la motivación por la búsqueda de soluciones mediadas. Pensar la mediación como doctrina y norma, es una muestra más de la importancia que le da la organización a su capital social, repercutiendo en la configuración y dialéctica de la identidad corporativa y, por ende, en la imagen corporativa percibida.

- Cláusula de Estilo: Influye de manera positiva en el estatus de transparencia que debe tener el proceso de mediación, hace el homólogo de un contrato alterno que delimita el sistema de solución de conflictos.

Es aplicable al reglamente interno de trabajo, donde se podría suscribir, si la alta dirección así lo determina, la mediación como primer paso ejecutable frente a los conflictos interpersonales, a manera de cláusula de mediación suscrita en el contrato, ampliada en el reglamento interno de trabajo y como parte estructural del Comité de Convivencia Laboral; Una cláusula de mediación contractual podría ser “Toda controversia derivada de este contrato, incluida las relativas a las relaciones laborales interpersonales y/o colectivas, se someterá para su resolución a mediación, administrada por el Comité e Convivencia Laboral; la designación de mediadores y la administración del proceso se regirán por las políticas internas de la organización". Es importante resaltar que no basta solo con una política general de bienestar y convivencia, hace falta instaurar la mediación como norma.

- Competitividad: Evidencia la influencia de este intangible en un futuro proceso de mediación, representa un factor diferenciador en cualquier ejercicio laboral y/o profesional.

Se suscribe como elemento diferenciador entre organizaciones de un mismo sector económico, va desde una cualidad de los miembros del equipo, hasta una premisa declarada en el direccionamiento estratégico de algunas organizaciones; dado que el conflicto suele irrumpir el normal desarrollo de los procesos, no es de extrañarse que esta elogiada cualidad se vea afectada por el mismo. En un escenario belicoso, la competitividad se ve afectada, pues nubla la capacidad de respuesta y adaptación, frente al cambiante mercado de productos y servicios en el que se mueven las organizaciones de naturaleza empresarial; de igual manera disminuye la capacidad del sujeto de integrar y alinear sus competencias personales, para proveer la mejor versión de su rol laboral en la ejecución de las tareas cotidianas adscritas a su contrato. 
- Confianza: Es la sumatoria de valores como credibilidad, fiabilidad, intimidad e interés personal, presentes en un sano equilibrio para abonar a la pronta resolución de los conflictos.

Este intangible es uno de los elementos que más se valora en el contexto organizacional, es la premisa de las relaciones cotidianas y el mejor escenario para desarrollarse profesionalmente; sus efectos se comprueban no solo en las dinámicas laborales, sino también en la fidelidad y productividad del cliente interno, al instaurar una política clara de mediación se promueve la percepción de confianza. Dado que un elemento clave de la fidelización tanto del cliente interno como del externo, es la percepción de confianza que se asocie con la organización, específicamente en las dinámicas relacionales propias de la interacción laboral, este intangible se constituye en el primer paso para posicionar la mediación provista por la empresa, como prioridad frente a los conflictos interpersonales.

- Confidencialidad: Es pensado desde la obvia percepción de vacuidad que frente a la intimidad genera el conflicto, y la necesaria disminución de ansiedad en él y entre las partes.

Dada la percepción de vulnerabilidad que suscita en el sujeto un escenario bélico, la gestión del recurso humano esta moral y éticamente llamada a cuidar con recelo la intimidad del sujeto labora, más aún cuando siente su ser vulnerado de alguna manera. Una garantía del cumplimiento de este intangible, adicional a los principios axiológicos dispuestos por la mediación, sería la inclusión de una clausula específica al interior de los protocolos de mediación diseñados por el Comité de Convivencia Laboral, propuesta que podría articularse como "Toda controversia administrada por el Comité e Convivencia Laboral, incluida las relativas a las relaciones laborales interpersonales y/o colectivas, deberá cuidad la integridad ética, moral y buen nombre de los sujetos labores que constituyan las partes en conflicto, toda vez que la confidencialidad es un derecho primario de la Constitución Política Colombiana; la filtración de información a miembros del equipo laboral, diferentes a los conflictuados y mediadores, sea genérica o específica del proceso de mediación, será sometida a investigación interna disciplinar y las sanciones se regirán por las políticas de la organización".

- Creatividad: Hace alusión a una competencia básica de todo mediador, para inferir en los elementos subyacentes al conflicto y orientarlos hacia la solución de este.

Se constituye en una de las competencias más apetecidas en el mercado laboral, pues trae consigo elementos dinamizadores de procesos humanos, estratégicos, y organizacionales en general; repensar los hechos de un conflicto requieren de esta cualidad, especialmente debido a la carga emocional que se maneja en un escenario belicoso. La mediación de los conflictos interpersonales laborales, está sujeta a pensar la misma realidad desde diferentes puntos de vista, llevando a las partes a recrear escenarios imaginarios donde se logra comprender la visión del contrapuesto, lo anterior es una versión de este intangible puesto en escena organizacional.

- Empoderamiento: Busca legitimar positivamente a los actores, reivindicando su valía personal posiblemente desdibujada en el conflicto.

Gran parte de los planes de inducción, capacitación y formación, están orientados al logro de esta competencia, pues es bien sabido el positivo efecto que para los procesos organizacionales tiene el estar liderados por sujetos que conocen, se ensamblan y comprometen con estos; siendo una cualidad ideal en los sujetos laborales, se constituye como esa fuerza de cohesión entre sujetos de conflicto y acuerdo conciliatorio, debido al efecto significativo que ejerce en una positiva auto-percepción y a la sensación de control que se recupera al terminar el conflicto. La mediación se constituye en la alternativa idónea para generar empoderamiento en los sujetos laborales, dado que incluye en sus principios axiológicos el protagonismo de las partes en conflicto. 
- Especialización: Como en el desarrollo de un arte, se vincula como ese factor diferenciador que da estatus de experto al sujeto mediador.

En el mundo del trabajo, el estatus de especialista se da por formación y/o experiencia, al cual se le da especial valía por el nivel de conocimiento que se tenga de determinados procesos.

Dado que la mediación no se encuentra inserta a los procesos organizacionales, se tendría que pensar en cómo vincular ciertas cualidades personales o procesos de formación para el logro de este intangible. Para el caso particular que propone este estudio, el escenario de la mediación administrada por el Comité de Convivencia Laboral, se debe incluir estrategia adicional a la básica reglamentada por el estado colombiano, por un lado, la selección (en coordinación con el área de talento humano) de él o los sujetos idóneos por sus competencias personales, y por otro la formación encaminada al desarrollo de competencias básicas de mediación.

- Estabilidad: Hace alusión a ese efecto alentador que produce el comprender, validar y entrar en acción, frente a la dinámica de la mediación misma.

Este es un concepto que ha mutado de manera perenne a lo largo del tiempo desde la perspectiva de sujeto y trabajo, predominantemente por el contexto económico de Colombia; aun así, establecer la mediación como proceso aportaría a la percepción de estabilidad, dado que el sujeto reconoce que existe un espacio constituido por la empresa para notificar controversias, deliberarlas y lograr acuerdos. Es común encontrar casos en los cuales la condición laboral percibida como inicua, no se evidencia tempranamente debió al imaginario colectivo que existe en torno a la percepción negativa que se asocia con quien suscribe el reporte; establecer la mediación de los conflictos interpersonales laborales como política y norma, permite disminuir este errado imaginario, aportando a la consolidación de este intangible al interior de las organizaciones.

- Felicidad: Precepto que se describe mejor desde su impacto para sujetos y comunidades, que conceptualmente, sustenta la filosofía Ganar/Ganar.

Uno de los elementos fundantes de la política de seguridad y salud en el trabajo, es la calidad de vida del sujeto, dentro de la cual existe consenso en la comunidad académica la felicidad juega un papel preponderante. Consabido el lugar que ocupa en la escala de necesidades humanas este intangible, así como la forma en la cual el conflicto interpersonal pone en detrimento su logro dentro del desarrollo del rol laboral; la mediación del conflicto llevada a buen término disminuye la sensación de cansancio emocional propia de los escenarios belicosos y aumenta la percepción positiva y esperanzadora del presente laboral, así como su futuro probable en un ambiente que promueva la felicidad.

- Fidelización: Se plantea como una estrategia intrínseca al ejercicio de la mediación, que busca fortalecer el compromiso mutuo entre las partes.

La cultura organizacional tiene como misión fundante aportar a la fidelización del cliente interno y externo, se podría pensar en la mediación de lo inicuo como una manifestación de compromiso por parte de la alta dirección, que redunda en este comportamiento esperado. Ejercer la mediación de los conflictos interpersonales laborales va aportando paulatina y continuadamente a la fidelización del sujeto suscrito a la organización, pues genera confianza y autonomía intrínseca, así como credibilidad a los procesos del direccionamiento estratégico.

- Flexibilidad: Esta habilidad de adaptación a los cambios provee elementos valiosos para la pronta solución de los desacuerdos. 
Se considera una habilidad blanda por excelencia para el desarrollo de carrera dentro y fuera de las organizaciones, los espacios de mediación proveen un ambiente donde la norma establecida prioriza al sujeto pese a su acto disruptivo, lo que tiene un efecto directo en la fidelización. Aunque el sujeto laboral se somete consciente y moralmente a asumir la norma explicita de la organización con quien suscribe el contrato, contar con la mediación de las condiciones percibidas como inicuas, provee un ambiente de flexibilidad frente a las consecuencias del conflicto, tales como los errores personales o de procedimiento, situaciones de comunicación de exacerbada emocionalidad y disrupciones en la rutina laboral, todos los anteriores asociados a imaginarios con carga negativa y susceptibles de perdida de la estabilidad al interior de la empresa.

- Garantía: Posee la virtud de producir en las partes una sensación de certeza frente al logro de sus objetivos, les permite a las partes confiar en el proceso en sí, aun dentro de la subjetividad de los posibles resultados de este.

Parte de la misión de un Comité de Convivencia Laboral está en ofrecer garantía de operatividad frente a todo escenario conflictivo posible, la garantía de un pago puntual, la prebenda por el logro de un indicador de gestión, la consecución de un ascenso, la prudencia frente a una notificación de una querella, entre otros, dibuja ambientes de trabajo éticos, confiables y seguros. La mediación como elemento prioritario frente a los conflictos interpersonales laborales, es en sí misma, una garantía de que la organización premia la cultura de paz y la salud mental del sujeto labora.

- Independencia: Se eleva como un intangible filosófico al englobar la primacía de principios morales como objetividad, buena fe e isonomía entre las partes, y el poder jurisdiccional de los MASC.

Si bien es cierto las organizaciones están en poder de determinar cuáles son los mejores planes y estrategias para dar cumplimiento a la norma, la inserción de la mediación de los conflictos interpersonales en las políticas laborales abonaría a un mayor posicionamiento de los métodos alternos en resolución de conflictos en el mundo del trabajo y las organizaciones; dado que una de las apuesta de la presente investigación es normalizar el reporte de las situaciones laborales inicuas que suscitan conflictos, y en respuesta, ratificar la figura del Comité de Convivencia Laboral como el escenario idóneo para la práctica de la mediación, se nutre tanto la independencia del sujeto quien libremente se compromete a la pacificación de los conflictos laborales, asi como la independencia jurídica que le da la legislación colombiana al Comité de Convivencia Laboral.

- Innovación: Esta premisa de la sociedad moderna, se visiona como una competencia del mediador tanto para abordar el conflicto como para inspirar a las partes hacia el acuerdo consensuado y de paso suscitarlo.

Es una premisa del mercado laboral presente, se podría decir también, el credo de la actual generación empresarial, lo que a su vez se constituye en uno de los argumentos para instar por una política de mediación al interior de las organizaciones, pues sería la primera vez que en este medio se propenda por visibilizar y normalizar los cotidianos y comunes conflictos interpersonales, y la consecuente convalidación de la disciplina de los MASC al interior de los procesos estratégicos. Gestionar el conocimiento organizacional, es pensar también en dinamizar cada vez más y mejor no solo los procesos estratégicos, sino también los efectos subyacentes como las dinámicas relacionales personales y colectivas; esta es una muestra de innovación desde la filosofía sinérgica con la que se mueve el mundo del trabajo y las organizaciones.

- Internacionalización: Responde al sentir de universalizar parámetros y principios de los MASC, esto produce en las partes la tranquilidad de estar amparados por convenciones internacionales, lo cual resulta muy oportuno para aquellas controversias donde las partes están radicadas en países diferentes. 
Son muchas las apuestas teóricas que existen en relación a mediar lo laboral, por ende, incluir como doctrina y norma el uso de la mediación frente al conflicto interpersonal como parte de las funciones adscritas al Comité de Convivencia Laboral, se constituye en un referente más para los MASC. Consabida es la necesidad de un discurso pacificador de carácter transversal a esta aldea global, fuera de las fronteras geográficas o políticas que separan los países, así como el terreno que con lujo de competencias ha ganado la filosofía de la mediación como el idioma de este anhelado discurso; apuestas como la de la presente investigación, abonan el terreno para seguir posicionando los MASC en los diferentes ámbitos de la vida humana, específicamente en el rol laboral, que es transversal a la vida misma.

- Liderazgo: Se erige como una competencia básica del mediador, en la cual logra alinear los objetivos particulares de las partes, produciendo como resultado la conciliación de los intereses.

Otra de las habilidades blandas deseables en el mercado laboral, por el lugar que ocupa en los procesos sujetos empoderados que logren guiar efectivamente procesos y personas; la dinámica de constitución del Comité de Convivencia Laboral supone esta característica dentro de los miembros que lo configuran, lo que abona terrenos a la configuración del sujeto mediador. Este intangible tiene muchas aristas en el contexto organizacional, por un lado, un buen líder sabe cuándo el ambiente laboral ha sido permeado por una situación negativa y puede instar a las partes a reportar y mediar, por otro lado, sabría reconocer cuando es mejor buscar a un tercero imparcial que medie entre él y alguien del equipo, en ambos contextos la mediación laboral del conflicto interpersonal es el protagonista.

- Mejora Continua: Volver más eficiente las dinámicas al interior de la mediación, tanto en lo procedimental como en lo relacional, bajo la premisa de que siempre se pueden hacer mejor las cosas.

Este se constituye en la premisa filosófica organizacional por excelencia, intangible aplicable a todo proceso personal y colectivo; una buena forma de verlo sería pensar la mediación de los conflictos interpersonales laborales como un resultado de aplicar este inangible, a su vez, cada proceso de mediación repercutiría de la mejora de los procesos a través de un buen clima laboral. Las organizaciones están en constante función de mejorar sus procesos, por tanto, la invitación está abierta para la inclusión de la mediación.

- Modernidad: Siendo la negociación un eje rector de la modernidad, este intangible pone a los MASC en el centro de un nuevo sistema social, como uno de los entes reguladores, proveyendo control y dinamismo al mismo tiempo.

Va de la mano de la filosofía de mejora continua, la naturaleza entrópica de las organizaciones, le obligan a buscar siempre adaptarse a los cambios del mercado y la sociedad en general, hoy el discurso internacional está abocado a los MASC, en un mundo cansado de fronteras. Pensar la mediación como respuesta a los conflictos interpersonales laborales, es apostarle a la sociedad moderna, metáfora donde el sujeto cada vez más busca la felicidad, la tranquilidad, la estabilidad y el menor desgaste innecesario de energía positiva, sociedad que se mueve y se transforma rápido, por lo cual no tiene tiempo para conflictuarse con otros.

- Monopolización del Procedimiento por las Partes: Si bien es cierto la palabra monopolización puede interpretarse negativamente, este intangible habla de la total autonomía que poseen las partes dentro de un proceso de mediación, convalidando a su vez uno de ellos principios de la mediación. 
Hacer parte de un proceso de mediación bajo esta premisa, aporta al desarrollo y fortalecimiento de la autonomía y el liderazgo, entre otras cualidades intangibles ya descritas anteriormente. La mediación es un acto donde los protagonistas dueños del conflicto, son a la vez dueños de la solución; empoderamiento, liderazgo, competencias transferibles, son tan solo algunas de las competencias buscadas y promovida por las organizaciones, y que se producen como efecto colateral de un proceso de mediación llevado a buen término.

- Motivación: Las situaciones de conflicto desgastan emocionalmente a las partes, lo que a su vez produce la percepción de ausencia visible de solución y disminuye la motivación para pensar proactivamente; este intangible es uno de los elementos que se reivindica en el sujeto en la medida que avanza la mediación, valor agregado resultado de los MASC.

Uno de los valores agregados de pensar en la mediación de los conflictos laborales interpersonales, es precisamente el positivo efecto que tiene en la autopercepción, sentirse dueño y constructor de un proceso. Si bien es cierto en el contexto organizacional, existes múltiples estrategias asumidas y adoptadas como políticas institucionales para motivar a la fuerza laboral, es la motivación intrínseca la más buscada. Un sujeto tranquilo con la norma explicita de la organización, que se siente incluido y visibilizado como valioso pese a sus discrepancias, es un sujeto motivado, a trabajar, a compartir, a dar lo mejor de sí, a mediar.

- Neutralidad: Este intangible va directo a los resultados de la mediación, los cuales no se verá permeados por juicios personales subjetivos, ni en procedimiento ni en ejecución final.

Es el primer paso para el logro de un ambiente adecuado para la mediación, más aún cuando en el ámbito laboral, el sujeto designado mediador al estar adscrito al comité de convivencia es a su vez par, mediador y autoridad revestida. Aunque esto se podría evidenciar como un conflicto de intereses, los delimitantes propios de la norma colombiana salvaguardarían el proceso (MinTrabajo, 2012). Así las cosas, los miembros del Comité de Convivencia Laboral designados como mediadores deberán realizar el proceso cuidando fielmente una posición siempre objetiva, proyectando en las partes la certeza de que esta allí para ayudarles a una pronta pacificación del conflicto interpersonal laboral, no para darle la razón a alguno, ni tampoco para comprobar responsabilidades; el objetivo del proceso de mediación es y siempre será, dinamizar el conflicto para llevarlo a buen término.

- No trae consecuencias Económico-Sociales: Su naturaleza practica nos habla del ahorro en tiempo, energía emocional, tramites y costas jurídicas, que tiene la implementación de los MASC versus sistema adversarial/jurídico.

Entablar un proceso de mediación en el espacio laboral, habla de la importancia que les da la organización a sus colaboradores, aunque podría considerase una pérdida de tiempo en cuanto se alejan provisionalmente a los trabajadores de su función contractual, tener un buen clima laboral es mucho más valioso. Las organizaciones han valorado históricamente el efecto colateral de los tiempos fuera, momentos en los cuales los sujetos no están ejerciendo su función contractual, pero que redundan en dinamización de los procesos; si el efecto de los tiempos fuera como capacitaciones, reuniones de festejo y salidas extramurales, es tan positivo, destinar un espacio para mediar los conflictos interpersonales laboral será además productivo.

- Objetividad: El distanciamiento emocional entre el mediador y el conflicto de los mediados, trae consigo la virtud de observarlo detalladamente desde diferentes ángulos, lo que a su vez tiene un efecto propósito y asertivo en la gestión del mediador que experimentadamente sabrá usarlo para la pronta solución de la controversia. 
Difícilmente los sujetos laborales perciben a un enviado de la alta dirección como persona objetiva, uno de los grandes retos que ha tenido que enfrentar el Comité de Convivencia Laboral en la práctica, es el posicionarse como efigie de objetividad; dada la filosofía pacificadora de la mediación, su ejercicio practicó bien llevado, proporcionaría un clima de confianza y camaradería, donde los trabajadores confían en las políticas institucionales, dando fe de esto a través del reporte de las condiciones y su consecuente voluntario sometimiento al ejercicio de mediación. Por otro lado, instaurar como política organizacional la mediación de los conflictos interpersonales, eleva la percepción de objetividad de la alta gerencia, dado que los sujetos laborales aprecian profundamente sentir validada su percepción de lo inicuo y emociones sin detrimento de la estabilidad.

- Perdón: Se presenta como un valor agregado, resultado de la mediación, donde las partes se une no solo en la placidez del fin del conflicto sino también en el inicio de una relación restaurada; sustenta las bases de un nuevo comienzo después del acuerdo.

Un ambiente laboral donde se está permitido fallar, quebrarse, es un ambiente que promueve la gestación del perdón, propio y ajeno. Este intangible no ha sido abordado como objeto de estudio en el marco organizacional, aunque se encuentra inmerso en el proceso de mediación, especialmente cuando se logra un acuerdo consensuado. El perdón se constituye en un intangible de alto valor en las relaciones humanas, en muchas ocasiones en medio de un ejercicio de mediación las partes en conflicto caen en la cuenta de sus erradas posturas y/o acciones, al pedir o recibir el perdón, se reivindica el sujeto, su subsanando la relación interpersonal.

- Prestigio: Ese lugar privilegiado que se gana solo con resultados efectivos y que las personas buscan bajo la premisa de quedar en buenas manos; mismo posicionamiento que los MASC han logrado y que sigue haciendo carrera a diferentes ritmos en cada país.

Es un lugar que se debe ganar toda área, grupo o comité, un buen nombre trae consigo posicionamiento y estatus, lo que redunda directamente en la confianza percibida. El prestigio o buen nombre es uno de los intangibles más valiosos cuando de identidad e imagen corporativa se trata, históricamente se ha teorizado en torno a el impacto que tiene este en el posicionamiento de la empresa en un determinado mercado, se aúna a la confianza y el liderazgo percibidos; por su parte, el Comité de Convivencia Laboral, tendrá que ganarse este prestigio, lo cual será una consecuencia de implementar adecuadamente la mediación de los conflictos interpersonales.

- Prevención del Conflicto: Bajo la premisa de un conflicto existente, trabaja en pro de que no se masifiqué, se reanude o mute hacia otra forma del mismo; se gestiona el conflicto desde la perspectiva de transformarlo mientras se evita su escalada.

Se constituye en parte fundante de las políticas de Bienestar Laboral, los planes de intervención suelen incluir espacios de formación personal donde se promueva la comunicación asertiva y la amable expresión emocional; pese a constituirse como ramas diferentes dentro de la habitual figura estratégica organizacional, tanto el área de talento humano, el de bienestar laboral y el Comité de Convivencia Laboral, trabajan desde diferentes estrategias en pro de mantener un ambiente laboral adecuado para la dinámica de la empresa. La prevención del conflicto es la base de toda relación humana, diferentes organizaciones a lo largo de la vida de un sujeto abanderan la causa, pero es en el mundo del trabajo donde se convierte en una filosofía de vida, en pro del cumplimiento satisfactorio del rol satisfactoriamente y de un clima laboral saludable. 
- Productividad: Al lograr que las partes vean desde otra perspectiva el conflicto, canalicen su energía hacia la meta de solucionarlo y reorienten sus esfuerzos para ir paso a paso llegando a puntos de convergencia, se convierten en partes activas del cambio; el sentimiento invocado por este intangible aumenta la auto-confianza de las partes e impacta positivamente en la mediación.

La percepción de que se atiende un conflicto personal de manera afectiva mantiene al sujeto con autoconfianza y esperanzador sobre el futuro probable. La productividad en forma y fondo es importante para toda organización y permea todos los procesos, consabido es que la mediación como política institucional, al dar autonomía a los sujetos y devolver el discurso pacificador, puede impactar positivamente en los procesos organizacionales. Por otro lado, un escenario belicoso afecta la productividad personal y por ende organizacional, el conflicto distrae al sujeto de su objeto contractual, lo lleva a un mundo de emociones que si se acrecientan pueden terminar en un coste para la salud mental y su paz interior.

- Rapidez: Una de las cualidades más apreciada de los métodos alternos, que si bien es cierto depende directamente de las partes, se erige como argumento rector de su posicionamiento frente al tradicionalmente congestionado proceso jurídico.

Es lógico que los grupos sociales deseen el buen término de las cosas con rapidez, esto no es ajeno a las organizaciones, donde tanto sujetos de conflicto como procesos afectados buscan agilizar los puntos de acuerdo para no afectar la dinámica laboral. El conflicto interpersonal laboral que trasciende, permea en la cultura organizacional un clima de tensión continua, sumado al desgaste administrativo que produce la intromisión de procesos jurídicos si se va a instancias judiciales; existe el imaginario colectivo de que la persona en conflicto se debe distanciar de las dinámicas sociales de la empresa hasta que no haya una respuesta legal a su litigio, lo cual fractura las relaciones y pone en detrimento la creatividad y el trabajo colaborativo en equipo.

- Re-asociación: Se abre paso como beneficio alterno a la mediación, al permitir a las partes resignificar sus roles en la vida del otro.

Dirimida una controversia se cambia la percepción del otro y de los hechos, lo que inicia como una situación irreconciliable termina siendo la oportunidad de conocer realidades alternas a una misma situación, este intangible es el inicio de nuevas formas de verse, convivir y porque no, trabajar en equipo. Al interior de universo organizacional es común que se formen subgrupos de trabajo, relaciones interpersonales afables que redundan en un sano clima laboral y en la dinamización de los procesos, la mediación del conflicto interpersonal es la herramienta por excelencia para subsanar las relaciones, y establecer nuevos y renovados vínculos.

- Reparación del Daño: Este es uno de los puntos centrales suscitado por la mediación, dado que son las partes quienes de manera autónoma delimitan los parámetros para el restablecimiento de su estado ideal

En gran parte de los conflictos laborales de naturaleza interpersonal, lo que busca el sujeto como reparación es la propia reivindicación de poder, control, valía y/o estatus quo posicionados en el imaginario personal y colectivo; en el caso particular de los conflictos interpersonales se inicia con lo que parece una latente necesidad de tener la razón pero subyacentemente se encuentran emociones difusas e intensas, reparar el daño va más allá de que el conflicto llegue a buen término, le devuelve al sujeto la sensación de paz interior y tranquilidad, contribuyendo a la construcción de la salud mental laboral.

- Reputación Corporativa: Condicionada por los valores corporativos, la reputación es la materialización de las relaciones entre los diferentes niveles que operan en una organización, su vínculo con los MASC está en la postura que asume la alta gerencia en relación con el conflicto. 
Una empresa que le apuesta a la resolución mediada de los conflictos es una empresa apetecida para trabajar, lo que a su vez redunda en la satisfacción laboral y por ende en los procesos, la calidez en la atención al cliente, entre otros. Como ya se ha comentado en anteriores intangibles, la identidad corporativa es un elemento de gran valía para las organizaciones y se configura elemento constituyente de la reputación, este intangible pone en evidencia todos los pequeños detalles del día a día que construyen el todo organizacional, donde el reconocimiento del mercado se da en múltiples términos tales como confiabilidad, calidad de servicio, atención al cliente, clima saludable de trabajo, y por qué no, espacios de mediación dinámicos.

- Satisfacción: La valoración positiva que se da en relación a un servicio prestado, es el mayor garante de un trabajo bien hecho, no solo se trata del logro de un objetivo.

La satisfacción como intangible tiene muchos universos posibles, en el caso de la suscrita investigación, es la percepción de estar en el lugar indicado para desarrollar todo el potencial profesional. Un elemento clave de la salud mental laboral es la percepción de satisfacción con el rol, el lugar y la función laboral que se ejerce, esta valoración positiva de la realidad que se vive construye identidad, vínculos y clima saludable.

- Seguridad Jurídica: El reconocimiento legal que se da al acuerdo de mediación, es y siempre debe ser, la mejor forma de promocionar los MASC; en el caso particular de las organizaciones el rol legal lo ejerce la alta gerencia.

Más allá de si el conflicto interpersonal es motivo de norma o no, que se pueda considerar mediable o no, normatizar un proceso provee el ambiente de credibilidad esperado; claridad de la norma, de los procesos, estándares, indicadores de gestión y de más elementos constituyentes del direccionamiento estratégico, son la clave para el logro de este intangible. Como se había mencionado en anteriores intangibles, cuando el sujeto laboral se encuentra en un ambiente que considera seguro, son más propensos a reportar el conflicto interpersonal y asumir un proceso de mediación.

- Simplicidad: La mediación como un arte, implica el intrincado y complejo asunto de simplificar el proceso; lenguaje, pasos, tiempos y acuerdos, todos en pro de la tranquilidad de las partes en conflicto bajo la premisa de la transparencia.

Volverlo norma no se trata de enclavar tramitología administrativa a algo tan natural como el conflicto interpersonal, implica quitarle poder al conflicto a tal punto, que permita ser rápidamente dirimible. La simplicidad como sinónimo de operatividad no de facilidad o medidas tibias, es la apuesta de la mediación laboral frente a los conflictos interpersonales; al volver cotidiano el ejercicio de mediación, irse evidenciando los casos exitosos de conflictos llevados a buen término, se podrá a futuro pensar en la normalización de los MASC en el ámbito de estudio de la presente investigación.

- Sinergia: Desde una perspectiva positiva, enmarca la necesidad de potencializar las competencias de las partes desde su naturaleza diversa.

Visibilizar el conflicto interpersonal y su coste para la cultura organizacional, es una forma de magnificar el flujo de los procesos, donde las personas se perciben humanas no temen equivocarse, lo que les permite a su vez soltar con mayor facilidad la carga perceptualmente negativa. Pensar en potencializar los procesos implementando alternativas diversas a las propuestas por la tradicional escuela administrativa, es mantener un pensamiento sinérgico, donde el mejoramiento continuo es la premisa filosófica.

- Transparencia: No solo es una cuestión de honor o un principio ético, pone en evidencia la necesaria normalización de la verdad, de la honestidad, con evidentes efectos positivos en ahorro de imaginarios sobrevalorados. 
Las organizaciones en general, tiene políticas de comunicación claras, donde se hace rendición de cuentas de ejercicios de liderazgo, esto convalida y posiciona a los tomadores de decisiones; una buena apuesta al normalizar la mediación, es proponerla como sinónimo transparencia en los procesos, así el sujeto laboral percibe el compromiso de la alta gerencia para con su desarrollo humano y se siente blindado por los procesos y las normas.

- Universalidad: Como la Declaración Universal de los Derechos Humanos, los Métodos Alternos se están erigiendo como la respuesta necesaria frente a una sociedad compleja y multiversa, que busca pronta y oportuna solución a las controversias; los principios rectores son un claro ejemplo de este proceso, que aún está escribiendo su historia.

Son muchas las investigaciones que hablan de los elementos de una buena cultura organizacional, aunque ninguna habla directamente de la mediación, si existen muchos elementos vinculantes entre el sujeto laboral y el mundo del trabajo; puede que no esté normatizada la mediación laboral de los conflictos interpersonales, pero su evidente importancia en el mundo de hoy se hace cada día más evidente. El sujeto ahora es ciudadano del mundo, y el mundo es una gran aldea global, esto implica pensar en un discurso pacificador de carácter universal, donde los MASC poseen doctrina, norma y experticia para proveerlo.

\section{Conclusiones}

Esta propuesta pone en contexto elementos de carácter perceptual, cuya intensidad en el contexto del conflicto está directamente relaciona con la posición que el sujeto cognitiva y afectivamente asume; uno de estos elementos, el intangible de la armonía converge en criterios y conceptos, con premisas tradicionalmente incluidas en la cultura organizacional, como ese ambiente deseable por el cual toda empresa debe propender (Martínez, 2009).

Pensar en la institucionalidad de la mediación como política estratégica es entonces el subsecuente y coherente paso, hacia organizaciones armónicas e inclusivas, que no solo atienden los desafíos propios del mercado en el cual se mueve su objeto económico, sino que asumen a los sujetos laborales como ese capital del siglo XXI (Piketty, 2014), cuidando con recelos su integralidad.

\section{Referencias Bibliograficas}

Ahumada, L. (2008). Conflicto, negoaciación, mediación y arbitraje: un acercamiento desde el ambito laboral. Psicoperspectivas, 9-20.

Almodóvar, J. M., \& Xu, Y. (2018). Habitar la naturaleza en armonía con el universo. Metafísica, geometría cósmica y orden social en la tradición arquitectónica china. Revista Iberoamericana de Filosofía, Política y Humanidades, 151-177.

Arastey, M. (2015). La mediación en los conflictos individuales de trabajo. Revista de Jurisprudencia.

Borrego, M. (2014). La mediación laboral: caracteristicas y efectos. Madrid: SIMA.

Brandstadter, J. (2006). Perspectiva para el análisis de la viabilidad de las empresas desde el enfoque de la clinica organizacional. Buenos Aires: Universidad de Buenos Aires.

Cabello, P. (2018). Teoría y gestión del conflicto. En F. Gorjón, \& R. Chávez, Manual de mediación penal, covil, familiar y justicia restaurativa (págs. 63-72). México: Tirant lo blanch.

Caicero, E. (2015). La Resolución de Conflictos Laborales: Un verdadero desafío para el área de Talento Humano en las Empresas. Bogotá: Universidad Militar Nueva Granada. 
Carnoda, D., \& Pestana, K. (2018). Liderazgo transformacional como herramienta que permita armonía organizacional en la división de reclutamiento y selección del ministerio del poder popular para eln transporte. Caracas: Universidad Nacional Experimental Simón Rodriguez.

Ceballos, P., Rolo, G., Hernández, E., Díaz, D., Paravic, T., Burgos, M., \& Barriga, O. (2015). Validación de la Escala Subjetiva de Carga mental de trabajo (ESCAM) enprofesionales de la salud de Chile. Universitas Psychologicas, 261-270.

Cedalise, C. (2019). Las particularidades de la mediación y arbitraje en los conflictos colectivos laborales. En O. Lugo, G. Gorjón, C. Cedalise, \& R. Soler, La transversalidad de los MASC. Unas perspectiva MéxicoPanamá (págs. 43-74). Monterrey: Universidad UANL.

Cedalise, C. (2020). Las Particularidades de la Mediación y y Arbitraje en los Conflictos Colectivos Labores. En O. Lugo, G. Gorjón, C. Cedalise, \& R. Soler, La Transversalidad de los MASC. Una Perspectiva MéxicoPanamá (págs. 43-74). México: Editorial Universitaria UANL.

Chiaventado, I. (2007). Administración de Recursos Humanos. El capita humano de las orgnaizaciones. México: McGraw-Hill.

CNC. (21 de Marzo de 1991). Función Pública. Obtenido de Congreso Nacional de Colombia: https://www. funcionpublica.gov.co/eva/gestornormativo/norma.php?i=6546

CNC. (5 de Enero de 2001). Organización de los Estados Americános. Obtenido de Congreso Nacional de Colombia: https://www.oas.org/dil/esp/Ley_640_de_2001_Colombia.pdf

CNC. (23 de enero de 2006). Congreso Nacional de Colombia. Obtenido de Diario Oficial No. 46.160: https:// oig.cepal.org/sites/default/files/2006_col_ley1010.pdf

Costantini, F. (2014). The supreme harmony: Analysis of the concept of harmony in the cosmological, ethical and social thought of zhang zai (1020-1078). Estudios de Asia y Africa, 9-30.

CRC. (23 de Enero de 2006). Congreso de la República. Obtenido de Observatorios de Igualdad de Género de America Latina y del Caribe: https://oig.cepal.org/sites/default/files/2006_col_ley1010.pdf

CRC. (16 de Julio de 2008). Ministerio de Tecnologías de la Información y las Comunicaciones. Obtenido de Congreso de la República: https://www.mintic.gov.co/portal/604/articles-3703_documento.pdf

CRC. (4 de Diciembre de 2008). Observatorio de Igualdad de Género de Ameria Latina y del Caribe. Obtenido de Congreso de la República: https://oig.cepal.org/sites/default/files/2008_col_ley1257.pdf

CRC. (31 de Julio de 2012). Super Intendencia Nacional de Salud. Obtenido de Congreso de la Republica de Colombia: https://docs.supersalud.gov.co/PortalWeb/Juridica/Leyes/L1566012.pdf

Cruz, N. (2014). «NIVEL DE SATISFACCIÓN LABORAL QUE POSEEN LOS EMPLEADOS DE LA DIRECCIÓN DE ÁREA DE SALUD DE HUEHUETENANGO Y SU RELACIÓN CON EL GENERO. HUEHUETENANGO: UNIVERSIDAD RAFAEL LANDÍVAR.

Decreto No. 1443, M. (31 de Julio de 2014). Decreto No. 1443. Bogotá, Colombia.

Fuentes, S. (2012). Satisfacción Laboral=Productividad. Quetzaltenango: Universidad Rafael Landivar.

Garza, C. (2016). La mediación laboral: una propuesta de aplicación en méxico. En P. Cabello, La multidisciplinariedad de la mediación y sus ámbitos de aplicación. (págs. 175-198). México: Tirant lo blanch.

Gil, P. (2012). Riesgos psicosociales en el trabajo y salud ocupacional. Revista peruana de Medicina Experimental y Salud Pública, 237-241.

Gil-Monte, P. (2009). Algunas razones para considerar los riegos psicosociales en el trabajo y sus consecuencias en la salud pública. Revista Española de salud pública, 169-173. 
González, P., \& Steele, J. (2020). El Rol del Mediador en el Proceso de Mediación de Conflictos: un Abordaje Según Doctrina y Legislación Comparada. En O. Lugo, G. Gorjón, C. Cedalise, \& R. Soler, La Transversalidad de los MASC. Una Perspectiva Médico-Panamá (págs. 165-198). México: Editorial Universidad UANL.

Gorjón, F. (2014). Escuela de pensamiento de los métodos alternos de solución de conflictos. Monterrey: Tendencias.

Gorjón, F. (2015). Teoría de la Impetración de la Justicia. Por la Necesaria Ciudadanización de la Justicia y la Paz. Comunitania, 113-131.

Gorjón, F. (2016). Mediación, ciencia social emergente. Comunitania, 9-19.

Gorjón, F. (2017). Mediación, su valor intangible y efectos operativos. Ciudad de México: Tirant Lo Blanch.

Gorjón, F. (2017). Mediación, su valor intangible y efectos operativos. Ciudad de México: Tirant Lo Blanch.

Gorjón, F. (2019). Mediador y facilitador; el mediador profesional del acuerdo, el facilitador profesional del perdon. Juris Poiesis, 229-252.

Gorjón, F. (2020). La mediación como política de bienestar. Politica Globalidad y Ciudadanía, 67-83.

Gorjón, F. (2020). Mediación como vía al bienestar y la felicidad. Ciudad de México: Tirant lo blanch.

Gorjón, F., \& José, S. (2020). Métodos alternativos de solución de conflictos. Monterrey: Oxford.

Gutiérrez, A., \& Viloría, J. (2014). Riesgos Psicosociales y Estrés en el ambiente laboral. Revista Científica Salud Uninorte, 1-3.

Han, B.-C. (2013). La sociedad de la transparencia. Barcelona: Herder.

Hospinal, S. (2013). CLIMA ORGANIZACIONAL Y SATISFACCIÓN LABORAL EN LA EMPRESA F Y D INVERSIONES S.A.C. Industrial Data, 75-78.

Lerechar, J. P. (2003). The Little Book of Conflic Transformatión. Good Books: Estados Unidos.

Lim, G., \& Carnevale, P. (1990). Contingencies in the mediation of disputes. Journal of Personality and Social Psychology, 259-272.

Mansilla, F. (2012). La mediación estratégica en los conflictos psicosociales en el trabajo. Medicina y Seguridad del Trabajo, 179-185.

Martínez, R. (2009). Efectividad de la mediación en conflictos laborales. Anda lucía: CARL.

Medina, R. (2007). Diferencias entre mediación y conciliación. Limamarc, 946-970. Obtenido de https:// limamarc-revista.blogspot.com/2007/12/diferencias-entre-mediacion-y.html

Ministero de Protección Social. (2013). Informe Ejecutivo Segunda Encuesta Nacional. Bogota. Obtenido de http://ccs.org.co/salaprensa/

MinSalud. (16 de Enero de 2019). Ministerio de Salud y la Protección Social. Obtenido de Gobiernos de Colombia: https://www.minsalud.gov.co/sites/rid/Lists/BibliotecaDigital/RIDE/DE/DIJ/resolucion089-de-2019.pdf

MinTrabajo. (30 de Abril de 2012). Ministerio de Trabajo. Obtenido de Gobierno de Colombia: https://www. mintrabajo.gov.co/documents/20147/45107/resolucion_00000652_de_2012.pdf/d52cfd8c-36f3-da894359-496ada084f20

MINTRABAJO. (30 de Abril de 2012). MINISTERIO DE TRABAJO. Obtenido de https://www.mintrabajo. gov.co/documents/20147/45107/resolucion_00000652_de_2012.pdf/d52cfd8c-36f3-da89-4359496ada084f20

MinTrabajo. (5 de Agosto de 2014). Ministerio de Trabajo. Obtenido de Gobierno de Colombia: https://www. mintrabajo.gov.co/documents/20147/36482/decreto_1477_del_5_de_agosto_de_2014.pdf/b526be6328ee-8a0d-9014-8b5d7b299500 
MinTrabajo. (31 de Julio de 2014). Ministerio del Trabajo Republica de Colombia. Obtenido de Gobierno de Colombia: https://www.mintrabajo.gov.co/documents/20147/36482/decreto_1443_sgsss.pdf/ ac41ab70-e369-9990-c6f4-1774e8d9a5fa

MinTrabajo. (15 de Abril de 2016). Ministerio de Trabajo. Obtenido de Gobierno de Colombia: https://www. mintrabajo.gov.co/documents/20147/0/DUR+Sector+Trabajo+Actualizado+a+15+de+abril++de+2016. pdf/a32b1dcf-7a4e-8a37-ac16-c121928719c8

MinTrabajo. (22 de Julio de 2019). Ministerio de Trabajo. Obtenido de Gobierno de Colombia: https://www. mintrabajo.gov.co/documents/20147/59995826/Resolucion+2404+de+2019-+Adopcion+bateria+riesgo +psicosocial\%2C+guia+y+protocolos.pdf

MinTrabajo. (13 de Febrero de 2019). Presidencia de la Republica. Obtenido de Gobierno de Colombia: https:// id.presidencia.gov.co/Documents/190219_Resolucion0312EstandaresMinimosSeguridadSalud.pdf

Montealegre, R. (2007). La solución de problemas cognitivos, una reflexión cognitiva sociocultural. Avances en Psicología Latinoamericana, 20-39.

Morales, M. (29 de Abril de 2018). Estas son las peleas más duras entre patronos y trabajadores. El Tiempo.

MPS. (Noviembre de 2007). Ministerio de la Protección Social. Obtenido de Observatorio de Drogas de Colombia: http://www.odc.gov.co/Portals/1/publicaciones/pdf/consumo/estudios/nacionales/ C003132007-diagnostico-situacional-sustancias-psicoactivas-poblacion-trabajadora-.pdf

MPS. (17 de Julio de 2008). Salud Capital. Obtenido de Ministerio de la Protección Social: http://www. saludcapital.gov.co/Documentos\%20Salud\%200cupacional/RESOL.\%202646\%20DE\%202008\%20 RIESGO\%20PSICOSOCIAL.pdf

Munduate, L., Butts, T., Medina, F., \& Martínez-Pecino, R. (2017). Guía para la Mediación Laboral. Quito: Raymi. Muñoz, F. (2001). Instituto de la Paz y los Conflictos de la Universidad de Granada. Obtenido de La Paz Imperfecta: https://www.ugr.es/ fmunoz/documentos/pimunozespa\%C3\%B1ol.pdf

OISS. (2014). Plan Nacional de Condiciones de Seguridad y Salud en el Trabajo 2013-2021. Bogotá: MinTrabajo Colombia. Obtenido de http://www.oiss.org/wp-content/uploads/2000/01/ PlanNacionalDeSeguridadySaludEnElTrabajo.pdf

OIT. (1984). Seguridad, higiene y medicina en el trabajo. Organización Internacional del Trabajo.

OIT. (2010). Riesgos emergentes y nuevos modelos de prevención en un mundo de trabajo en transformación. Ginebra: OIT. Obtenido de Riesgos emergentes y nuevos modelos de prevención en un mundo de trabajo en transformación.

OIT. (2011). Sitema de gestión de la seguridad y salud en el trabajo. Italia: OIT. Obtenido de https://www. ilo.org/wcmsp5/groups/public/@ed_protect/@protrav/@safework/documents/publication/ wcms_154127.pdf

OIT. (2017). Objetivos de Desarrollo Sostenible: Manual de referencia Sindical sobre la Agenda 2030 para el Desarrollo Sostenible. Ginebra: OIT. Obtenido de https://www.ilo.org/wcmsp5/groups/public/--ed_dialogue/---actrav/documents/publication/wcms_569914.pdf

OMS. (2010). Entornos laborales saludables. Biblioteca de la OMS. Obtenido de https://www.who.int/ occupational_health/evelyn_hwp_spanish.pdf

ONU. (2015). Objetivos de Desarrollo del Milenio. Nueva York: Naciones Unidas. Obtenido de http://mdgs. un.org/unsd/mdg/Resources/Static/Products/Progress2015/Spanish2015.pdf

ONU. (2018). La agenda 2030 y los objetivos de desarrollo sostenible: una oportunidad para América Latina y el Caribe. Santiago: CEPAL. Obtenido de https://repositorio.cepal.org/bitstream/ handle/11362/40155/24/S1801141_es.pdf 
Pastor, E. (2013). La Mediación como Herramienta de Intervención Social. En F. Gorjón, \& A. López, Estado del Arte de la Mediación (págs. 99-124). España: Aranzadi, SA.

Piketty, T. (2014). El capitar del siglo XXI. México: Fondo de Cultura Económica.

SERCLA. (4 de Febrero de 2004). REGLAMENTO DE FUNCIONAMIENTO Y PROCEDIMIENTO DEL SISTEMA EXTRAJUDICIAL DE RESOLUCIÓN DE CONFLICTOS LABORALES DE ANDALUCÍA. Obtenido de SERCLA: https://personal.us.es/josemgomez/documentos/Reglamento\%20SERCLA\%20 conflictos\%20 colectivos.pdf

Silva, G. (2008). La Teoría del Conflicto. Un Marco Teórico Necesario. Prolegómenos. Derechos y Valores, 2943.

Silvia Henao, D. C.-M. (2014). Relación entre factores psicosociales negativos y el síndrome de burnout en el personal sanitario de Florencia (Caquetá, Colombia).

Vargas, L. A. (2019). Análisis de los imaginarios de la cultura organizacional que tiene un grupo de colaboradores de la entidad metro cali S.A. respecto a la comunicación interna. Santiago de Cali: Universiad Autonoma de Occidente. 